\title{
Dynamic links between shape of the eddy viscosity profile and the vertical structure of tidal current amplitude in bays and estuaries
}

\author{
Wei Chen ${ }^{1}$ - Huib E. de Swart ${ }^{1}$
}

Received: 10 June 2015 / Accepted: 28 December 2015 / Published online: 5 February 2016

(C) The Author(s) 2016. This article is published with open access at Springerlink.com

\begin{abstract}
Several field studies in bays and estuaries have revealed pronounced subsurface maxima in the vertical profiles of the current amplitude of the principal tidal harmonic, or of its vertical shear, over the water column. To gain fundamental understanding about these phenomena, a semianalytical model is designed and analysed, with focus on the sensitivity of the vertical structure of the tidal current amplitude to formulations of the vertical shape of the eddy viscosity. The new analytical solutions for the tidal current amplitude are used to explore their dependence on the degree of surface mixing, the vertical shape of eddy viscosity in the upper part of the water column and the density stratification. Sources of surface mixing are wind and whitecapping. Results show three types of current amplitude profiles of tidal harmonics, characterised by monotonically decreasing shear towards the surface, "surface jumps" (vertical shear of tidal current amplitude has a subsurface maximum) and "subsurface jets" (maximum tidal current amplitude below the surface), respectively. The "surface jumps" and "subsurface jets" both occur for low turbulence near the surface, whilst additionally the surface jumps only occur if the eddy viscosity in the upper part of the water column decreases faster than linearly
\end{abstract}

Responsible Editor: Emil Vassilev Stanev

Electronic supplementary material The online version of this article (doi:10.1007/s10236-015-0919-6) contains supplementary material, which is available to authorized users.

Wei Chen

w.chen4@uu.nl

1 Institute for Marine and Atmospheric research Utrecht, Princetonplein 5, 3584CC Utrecht, The Netherlands to the surface. Furthermore, "surface jumps" take place for low density stratification, while and "subsurface jets" occur for high density stratification. The physics causing the presence of surface jumps and subsurface jets is also discussed.

Keywords Turbulent mixing - Density stratification . Turbulent boundary layer $\cdot$ Surface jump $\cdot$ Subsurface jet

\section{Introduction}

Tides are often a significant, if not dominant, constituent of the water motion in bays and estuaries. Knowledge of the spatial and temporal characteristics of tides is important, as they play a key role in, e.g. the mixing and transport of salt, sediment and nutrients. Nowadays, surface tides and tidal currents are successfully simulated with detailed numerical models (e.g. Warner et al. 2005; Burchard and Hetland 2010). These studies showed explicit results of tides obtained with models that apply second-order closure schemes for eddy viscosity. It appears that, in order to achieve good representations of the vertical structure of tidal currents, sophisticated formulations are required for vertical eddy viscosity, the latter representing the degree of vertical mixing. When the main interest is rather in gaining fundamental insight into tidal dynamics, i.e. to identify and analyse processes that cause a specific observed feature, such models are less suitable tools, owing to their complexity. For such purposes, idealised models have been developed and analysed, which rely on simple formulations of eddy viscosity (Johns 1966; Ianniello 1977; Friedrichs and Hamrick 1996; Huijts et al. 2006; Winant 2007; Zitman and Schuttelaars 2012). 
This study focuses on two specific phenomena that appear in vertical profiles of the current amplitude of a single tidal harmonic component and which are, as yet, not well understood. The first is called a surface jump (SJ-I) and it is related to the presence of a subsurface maximum in the shear of the tidal current amplitude (i.e. in the vorticity). It was observed by Heaps and Jones (1981) in Liverpool Bay, but they were unable to capture it with their model that uses a simple formulation for eddy viscosity. The second feature, called a subsurface jet (SJ-II), refers to the presence of a subsurface maximum in the $\mathrm{M}_{2}$ tidal current amplitude itself. It was observed by Jay and Musiak (1996) in the Columbia estuary and by Jiang et al. (2013) in the Yangtze estuary.

Note that surface jumps and subsurface jets as defined above are not identical to surface and subsurface maxima in the instantaneous current during the ebb or flood phase. This is because the instantaneous current comprises all tidal harmonics, including overtides and residual currents. For example, subsurface maxima during flood are frequently detected, but as already explained by Jay and Musiak (1994), they may result from the joint effect of a primary tidal component (which shows no subsurface maximum in its current amplitude) and a residual flow and overtides. Likewise, Lacy et al. (2003) showed that of subsurface velocity maxima result from lateral tidal advection of slower moving surface water from the margins of the estuarine channel.

The objective of the present study is to provide an explanation for the SJ-I and SJ-II phenomenon in the vertical profile of the current amplitude of a primary tidal constituent, as is described above. Using a theoretical model, Lamb (1932) and Prandle (1982) showed that in unstratified seas, tidal current amplitude maxima occur below the water surface if the thickness of the frictional boundary layer is much smaller than the water depth. Such conditions would require depths of at least several hundreds of meters. The way to obtain a smaller boundary layer thickness in shallow bays and estuaries is by means of density stratification. In particular, Geyer et al. (2000) showed that in partially mixed estuaries, the maximum viscosity occurs only a few meters above the bottom, which is called the well mixed part of the boundary layer. Moreover, a recent numerical study by Cheng et al. (2013) showed that, with increasing density stratification in an estuary, the maximum eddy viscosity becomes smaller and its location shifts towards the bottom.

These considerations motivate the hypothesis of the present study, viz. the emergence of surface jumps and subsurface jets is related to a specific distribution of eddy viscosity with depth, which results from bottom turbulence, surface mixing and density stratification.

To test the formulated hypothesis, an idealised model has been designed, which allows for new analytical solutions for tidal flow. Using these new solutions, a sensitivity study of the characteristics of tidal current amplitude profiles to parameters that characterise a family of eddy viscosity profiles is conducted.

The subsequent sections are organised as follows: The model and methods are introduced in Section 2. In Section 3, vertical structures of tidal current amplitudes resulting from different eddy viscosity profiles are presented. Section 4 contains the discussion, including a physical interpretation of the results, and conclusions are presented in Section 5.

\section{Model and methods}

\subsection{Model}

The along-estuary flow is governed by the shallow water momentum balance in terms of a scaled vertical coordinate $\sigma=(z-\eta) / D$. Here, $z$ is a vertical coordinate, $z=0$ is the undisturbed water level, $z=\eta$ is the free surface, $z=-h$ the bottom and $D=h+\eta$ is the total depth. Thus, $\sigma=-1$ and $\sigma=0$ represent the bottom and and the free surface, respectively. This choice is convenient because often field observations (Bowden and Sharaf El Din 1966; Lane et al. 1997; Jiang et al. 2013) are measured and analysed at levels $\sigma=$ constant. It is assumed that the amplitude $Z$ of sea surface variation $\eta$ is small compared to the undisturbed water depth $h$. This identifies a small parameter $\varepsilon=Z / h$. After applying the perturbation analysis similar to Ianniello (1977), the model equation at leading order reads

$$
\frac{\partial u}{\partial t}=-g \frac{\partial \eta}{\partial x}+\frac{1}{h^{2}} \frac{\partial}{\partial \sigma}\left(A_{v} \frac{\partial u}{\partial \sigma}\right) .
$$

Here, $u$ denotes the local along-estuary velocity, $t$ is time, $g=9.8 \mathrm{~ms}^{-2}$ is gravitational acceleration and $\partial \eta / \partial x$ is the along-estuary gradient of the free surface. Note that for small $\varepsilon, \sigma \simeq z / h$, hence at this order of approximation output of Eq. 1 at $\sigma$-levels can be straightforwardly transformed to output at $z$-levels and compared with field data collected at $z$-coordinates. (e.g. Jay and Musiak 1996; Geyer et al. 2000). This equation has been shown to capture the gross characteristics of observed tidal flow quite well, in case that an appropriate formulation for the vertical eddy viscosity coefficient $A_{v}$ is chosen (Friedrichs and Hamrick 1996; Huijts et al. 2009). Note that in shallow bays, where depth is relatively large and flow is unconstrained by side walls, the longitudinal tidal dynamics may be also affected by Coriolis veering (Prandle 1982; Soulsby 1983; Souza 2013). This will be further discussed in Section 4.

The eddy viscosity coefficient $A_{v}$ is formulated as

$A_{v}=\kappa\left|u_{*}\right| h A_{\sigma}$. 
where $\kappa=0.41$ is the von Karman's constant, $u_{*}$ is the friction velocity and $A_{\sigma}$ describes the profile of the eddy viscosity coefficient. Note that at the present order of approximation $(\varepsilon \ll 1) \sigma=z / h$, hence the function $A_{\sigma}$ does not depend on time.

At the bottom, the no-slip condition is applied:

$u=0 \quad$ at $\quad \sigma=-1+\sigma_{0}$.

In this expression, formally $\sigma_{0}=z_{0} /(h+\eta)$ and $z_{0}$ denotes the local roughness length. In the present model $\eta \ll h$, consequently

$\sigma_{0}=\frac{z_{0}}{h}$

At the free surface, it is assumed that tidal motion is stress free and satisfies the kinematic boundary condition

$A_{v} \frac{\partial u}{\partial \sigma}=0 \quad$ at $\quad \sigma=0$

The along-estuary gradient of the free surface reads

$\frac{\partial \eta}{\partial x}=\frac{d N}{d x} \cos (\omega t)$

with $d N / d x$ prescribed and $\omega$ is the imposed radian frequency of the tide.

\subsection{Formulation of eddy viscosity}

In this study, the water column consists of two layers. A continuous family of profiles of $A_{\sigma}$ is considered, which include both classical profiles as well as profiles that mimic

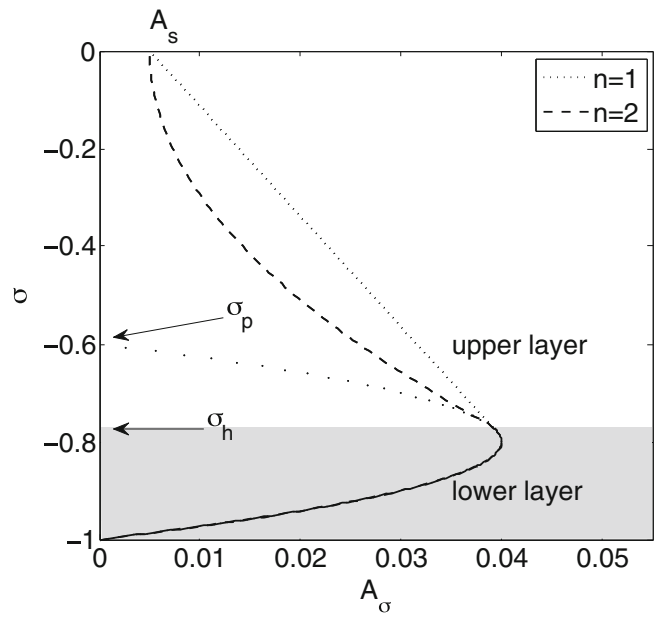

Fig. 1 Typical vertical distributions of the vertical structure of eddy viscosity $A_{\sigma}$. The dotted line in the upper layer indicates the extension of function Eq. 7 into the upper layer, to show the location of the level $\sigma=\sigma_{p}$ key aspects of observed profiles of time-mean eddy viscosity. The formulation for $A_{\sigma}$ in Eq. 2 reads

$A_{\sigma}=(\sigma+1)\left(\sigma_{p}-\sigma\right), \quad-1 \leq \sigma \leq \sigma_{h} ; \quad$ (lower layer),

$A_{\sigma}=\left(A_{I}-A_{S}\right)\left|\frac{\sigma}{\sigma_{h}}\right|^{n}+A_{S}, \quad \sigma_{h} \leq \sigma \leq 0 ; \quad$ (upper layer),

in which $A_{I}=\left.\left(\sigma_{h}+1\right)\left(\sigma_{p}-\sigma_{h}\right) \equiv A_{\sigma}\right|_{\sigma=\sigma_{h}}$.

Thus, Eqs. 7a and b contain four parameters, viz. $\sigma_{p}, \sigma_{h}$, $A_{S}$ and $n$ (Fig. 1). The introduction of two layers is based on the argument that the length scale for mixing is related to the thickness of bottom boundary layer (Stacey and Ralston 2005; Ralston et al. 2008). Hence, the boundary layer height scales with $\left(1+\sigma_{p}\right)$; more details will be discussed in Section 4.

Physical arguments (e.g. the law of the wall) imply that there are three constraints on the eddy viscosity. First, $d A_{\sigma} / d \sigma$ is positive near the bottom. Second, $d A_{\sigma} / d \sigma \leq 0$ in the upper layer, i.e. it is assumed that the turbulent mixing generated at the surface (by wind stress, breaking waves, etc.) is never larger than the maximum turbulent mixing induced by the tide. Third, $d A_{\sigma} / d \sigma$ is continuous in the entire water column. This constraint is accordance with Ianniello (1977) and Cheng et al. (2013).

The first two constraints imply $\left(1+\sigma_{p}\right)>0$ and $A_{S} \leq$ $A_{I}$. Moreover, these constraints suggest that $A_{\sigma}$ attains its maximum in the lower layer. It follows straightforwardly that this maximum value is $A_{\sigma, \max }=\left(1+\sigma_{p}\right)^{2} / 4$ and it occurs at $\sigma=\left(\sigma_{p}-1\right) / 2$, which must be below $\sigma=\sigma_{h}$. Thus $\sigma_{h} \geq\left(\sigma_{p}-1\right) / 2$ and the value of is determined by
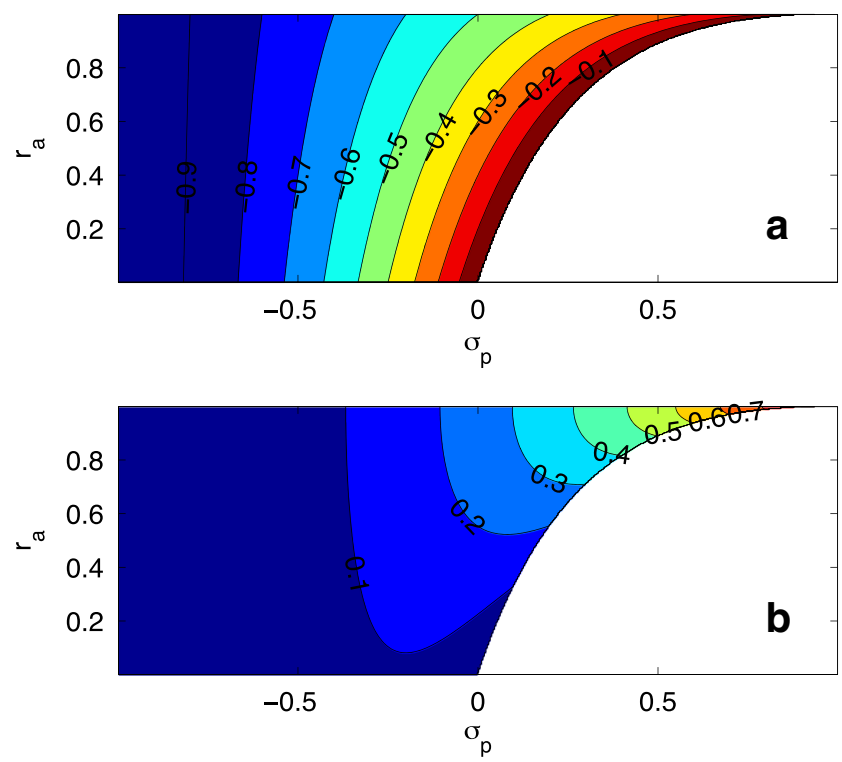

Fig. 2 Contour plots of parameters $\sigma_{h}$ (a) and $A_{I}$ (b), defined in Eq. 7, as functions of the free parameters $r_{a}$ and $\sigma_{p}$ when $n=2$ 
the third constraint. Finally, since $\sigma_{h} \leq 0$ (see Eq. 7b), it follows $\sigma_{p} \leq 1$, thereby overall values of parameter $\sigma_{p}$ vary between -1 and 1 . A parameter $r_{a}=A_{S} / A_{\sigma, \max }$ is introduced hereafter to indicate the relative degree of surface mixing with respect to maximum mixing. The exponent $n$ determines the shape of $A_{\sigma}$ in the upper layer $(n=1$ linear, $n=2$ parabolic, etc). Note that $r_{a}=1$, together with the third constraint, implies a constant eddy viscosity $A_{\sigma}=A_{\sigma, \max }$ in the upper water layer and therefore covers the case that $n=0$. Hence, the formulation of eddy viscosity contains three independent free parameters, i.e. $\sigma_{p}, r_{a}$ and $n$.

The dependencies of parameters $\sigma_{h}$ and $A_{I}$ on $\sigma_{p}, r_{a}$ and $n$ are shown in Fig. 2. By choosing values of $\sigma_{p}, n$ and $r_{a}$, the formulation Eq. 7 is able to mimic different shapes of eddy viscosity profiles presented in earlier studies (Fig. 3), such as the combined parabolic and vertical invariant profile employed by Ianniello (1977) (Fig. 3a), and the parabolic profile (Fig. 3b) studied by Burchard and Hetland (2010) and Zitman and Schuttelaars (2012). Two typical profiles that manifest themselves if the water column is highly stratified are shown by Burchard and Hetland (2010), as well as by Cheng et al. (2013). The formulation in Eq. 7 is also able to mimic these two profiles (Fig. 3c, d). Note that solutions can be obtained for any finite $r_{a}$, no matter how small its value. Thus the choice $r_{a} \ll 1$ and $\sigma_{h}=0$ yields the parabolic eddy viscosity profile.

\subsection{Linearisation of the friction}

By definition, the friction velocity is related to the kinematic bottom shear stress, as

$u_{*}\left|u_{*}\right|=\left.\frac{A_{v}}{h} \frac{\partial u}{\partial \sigma}\right|_{\sigma=-1+\sigma_{0}}$.

Thus, the momentum equation (Eq. 1) with $A_{v}$ closed Eq. 2 is nonlinear. To linearise the equation, here a representative constant $\tilde{u}_{*}$ is introduced to replace $\left|u_{*}\right|$ in Eqs. 2 and 8 . It is assumed that, in a tidally dominant estuary or bay, with this representative $\tilde{u}_{*}$, the modified bottom shear stress gives the same energy dissipation rate as the nonlinear bottom stress $\rho u_{*}\left|u_{*}\right|$ (Lorentz 1922; Kajiura 1964; Zimmerman 1982). The consequence of linearisation of Eq. 1, together with the forcing as given in Eq. 6 is that $u$ is harmonic in time and moreover, $u_{*}$ is harmonic in time, with amplitude $\hat{u}_{*}$. Development of the energy criterion yields

$\tilde{u}_{*}=\frac{8}{3 \pi} \hat{u}_{*}$,

which hereafter is referred to as the representative friction velocity. Hence, for a selected $A_{\sigma}$, analytical solutions for tidal flow $u$ are constructed that depend on $\tilde{u}_{*}$. With prescribed roughness height in the estuarine channel, an iteration procedure is used to determine the linearised bottom shear stress and the eddy viscosity coefficient.

\subsection{Analytical solutions}

Analytical solutions for the tidal currents governed by Eqs. $1-9$ are

$u=\Re\left\{\hat{U} e^{-i \omega t}\right\}$,

where $\Re$ denotes taking the real part of a complex variable. Furthermore, $\hat{U}$ is the complex, $\sigma$-dependent amplitude of the tidal current. Note that $\hat{U}=U e^{i \phi}$, with $U$ the realvalued amplitude and $\phi$ the phase. Substitution of Eq. 10 into Eq. 1 and using Eq. 2, with $\left|u_{*}\right|$ replaced by $\tilde{u}_{*}$, and using Eqs. 3-7, it follows that

$\hat{U}=-i \frac{g}{\omega} \frac{d N}{d x} p$.

In this result, $p$ is a function of $h$ and $\sigma$. Explicit analytical expressions for $\mathrm{p}$ are given in Appendix A for the cases $n=$ $0, n=1$ and $n=2$. For other values of $n$, solutions in the lower layer are still analytical, but for the upper layer $p$
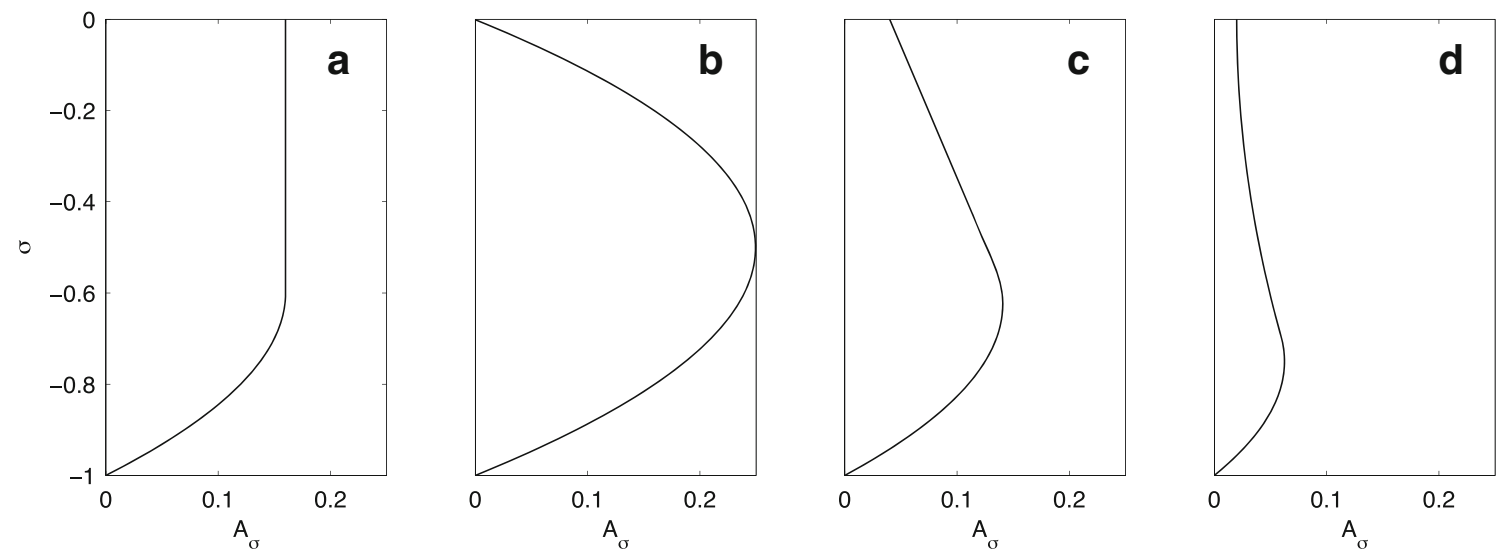

Fig. 3 Different vertical profiles of eddy viscosity as governed by Eq. 7 : a. $\sigma_{p}=-0.3, r_{a}=0.99$; b. $\sigma_{p}=-0.001, r_{a}=0.01$ c. $\sigma_{p}=$ $-0.3, r_{a}=0.25 ;$ d. $\sigma_{p}=-0.6, r_{a}=0.25$ 

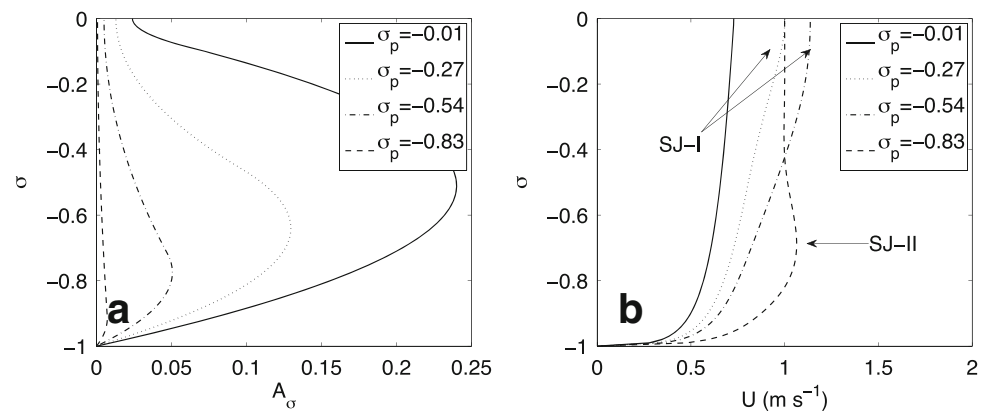

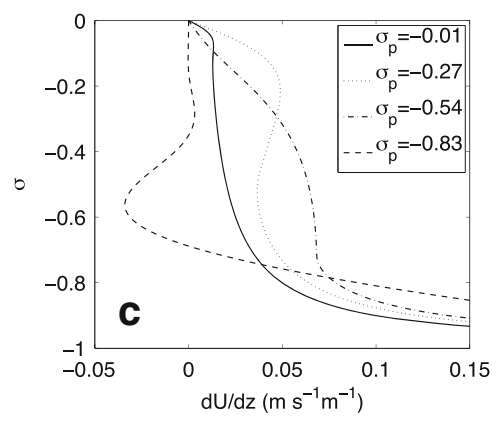

Other parameter values as in Table 1. Values for representative friction velocity $\tilde{u}_{*}$, as defined by Eq. 9 are $0.033,0.03,0.02$ and $0.01 \mathrm{~m} \mathrm{~s}^{-1}$

\section{Results}

Figure 4 shows eddy viscosity, tidal current amplitude and its vertical shear (proportional to vorticity) for $n=2, r_{a}=$ 0.2 and varying $\sigma_{p}$ for the default parameter values given in Table 1. The panels in this figure reveal that for $n=2$ there are combinations of $\sigma_{p}$ and $r_{a}$ that yield different vertical structures of the current amplitude. As is illustrated in Fig. $4 \mathrm{~b}$, the profiles of the tidal current amplitude for $\sigma_{p}=-0.27$ and -0.54 show a surface jump (SJ-I), as follows from the presence of a subsurface maximum in the tidal shear for these parameter values (Fig. 4c). In contrast, for $\sigma_{p}=-0.83$, the profile of the tidal current amplitude shows a subsurface jet (SJ-II); the value of parameter $\xi$, as defined in Eq. 12, is $\xi=0.13$.
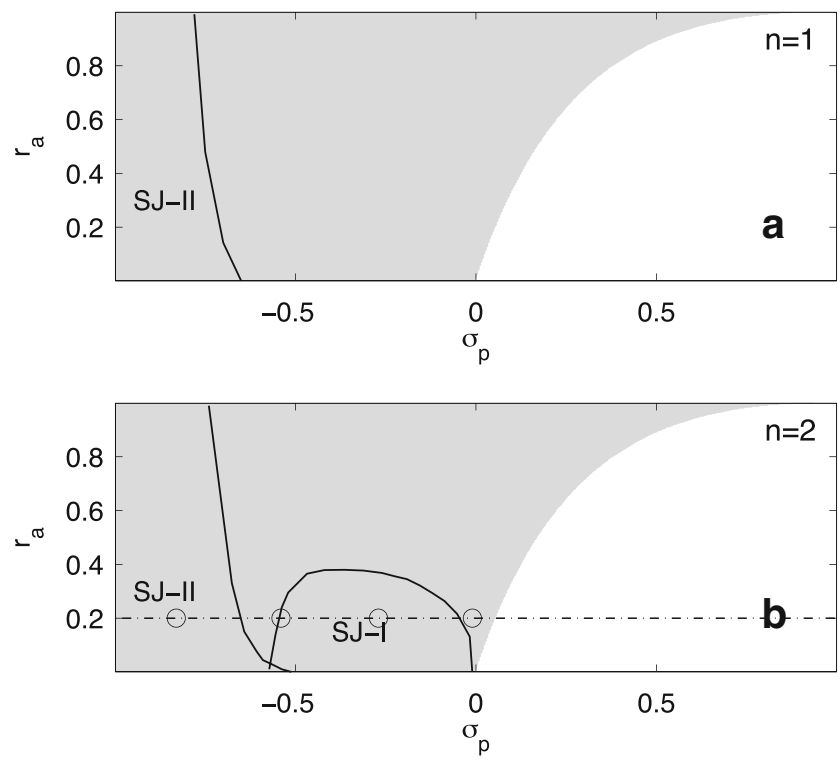

Fig. 5 Regions in the $\sigma_{p}-r_{a}$ parameter space where the SJ-I (surface jump) and/or SJ-II (subsurface jet) phenomena occur. Panels a and b show results for $n=1$ and $n=2$, respectively. The grey-shaded area indicates values of $\sigma_{p}$ and $r_{a}$ that are physically possible. The circles on the dashed line in panel $\mathbf{b}$ indicate the parameter values that were used in Fig. 4 

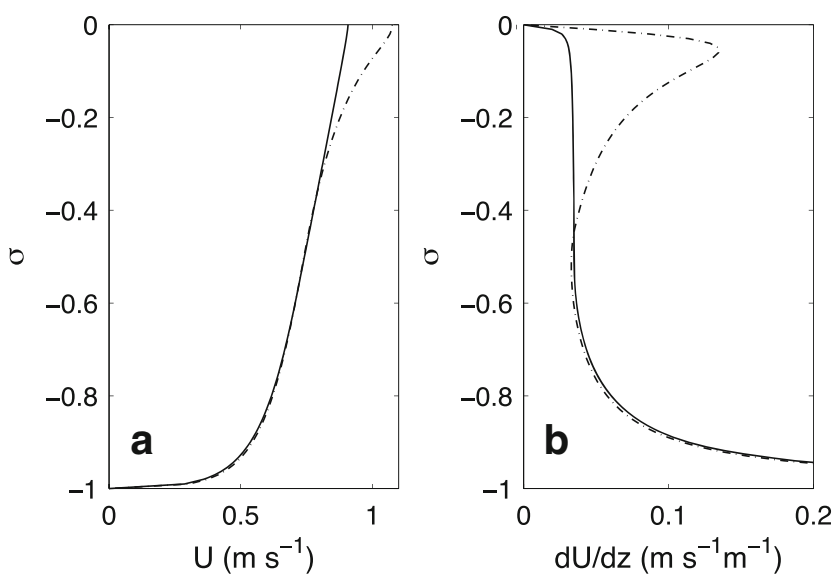

Fig. 6 a The tidal current amplitude computed with the model for $\sigma_{p}=-0.25, r_{a}=0.01, n=1$ (solid line) and $n=2$ (dashed line). b The corresponding vertical gradient of the tidal current amplitude. Other parameter values as in Table 1

Figure 5 shows the regions in the $\sigma_{p}-r_{a}$ parameter space (for $n=1$ and $n=2$, respectively) where the SJ-I/II phenomena occur. The SJ-I phenomena are found in the lower middle part of the diagram for $n=2$ (Fig. 5b). In the case when $n=1$, the SJ-I phenomenon is not found. Instead, for values of $\sigma_{p}$ and $r_{a}$ where SJ-I is found if $n=2$, the current amplitude in the case $n=1$ increases almost linearly to the surface, as is shown in Fig. 6a. Correspondingly, the velocity shear, i.e. the vorticity becomes a constant in the upper part of the water column, before reaching the surface (Fig. 6b). These results suggests that the SJ-I occurs if the eddy viscosity in the upper layer of water column decreases faster than linearly towards the surface $(n>1)$.

Another interesting result is that the SJ-II phenomenon is found in the left part of the diagrams shown in Fig. 5, both for $n=1$ and $n=2$. Note that in the latter case, the areas where SJ-I and SJ-II phenomena occur partly overlap, viz. between $\sigma_{p}=-0.5$ and -0.6 . Indeed, as is shown in Fig. 7, for parameter values in the latter area the tidal current amplitude reveals both SJ-I/II phenomena. The vorticity has a negative extremum near the surface of water column and two positive extrema in the interior. Moreover, the maximum current amplitude is found in the interior of the water column.

As has been stated in the previous section, the solutions for tidal flow were obtained by an iteration procedure to determine the friction velocity $u_{*}$. To quantify the sensitivity of the model results to the choice of the bottom roughness hight $\sigma_{0}$, the friction velocity was computed for different values of the bottom roughness length $z_{0}$. The friction velocity, which relates to the shear stress at the bottom, is not affected by the turbulence from the water surface and is therefore not sensitive to the choice of $r_{a}$ and $n$. A transect for $r_{a}=0.01$, with different $\sigma_{p}$, was selected to show the
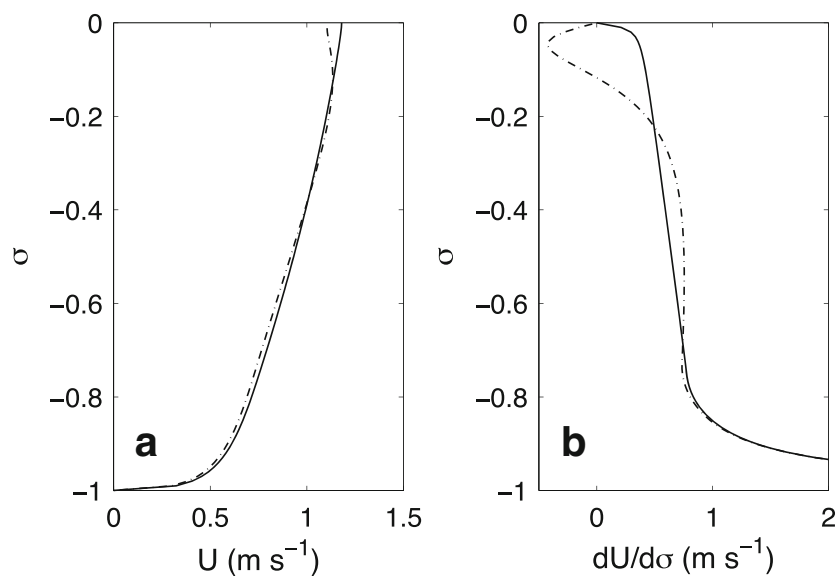

Fig. 7 a The tidal current amplitude computed with the model for $\sigma_{p}=-0.57, r_{a}=0.01, n=1$ (solid line) and $n=2$ (dashed line). b The corresponding vertical gradient of the tidal current amplitude. Other parameter values as in Table 1

representative friction velocity $\left(\tilde{u}_{*}\right)$ computed for three different values of the dimensionless bottom roughness length $\sigma_{0}=z_{0} / h$, which represent respectively a smooth bottom $\left(\sigma_{0}=0.2 \times 10^{-3}\right)$, a moderately rough bottom $\left(\sigma_{0}=\right.$ $\left.1 \times 10^{-3}\right)$ and a rough bottom $\left(\sigma_{0}=2 \times 10^{-3}\right)$. Results are shown in Fig. 8. The representative friction velocities during the tidal cycle are in general lower than $0.035 \mathrm{~m} \mathrm{~s}^{-1}$ and show the same dependency on $\sigma_{p}$. No linear relation is found between the representative friction velocity and $\sigma_{p}$. Moreover, the difference in representative friction velocity between the smooth and rough bottom is small (less than $0.005 \mathrm{~m} \mathrm{~s}^{-1}$ ). With the representative friction velocity, the eddy viscosity is computed and the results show that the values of the eddy viscosity coefficient range from 0 to $0.045 \mathrm{~m}^{2} \mathrm{~s}^{-1}$, which are close to the values observed in the field (Bowden and Sharaf El Din 1966; Jay and Musiak 1996; Geyer et al. 2000) or calculated by numerical models (Stacey et al. 2008; Cheng et al. 2013).

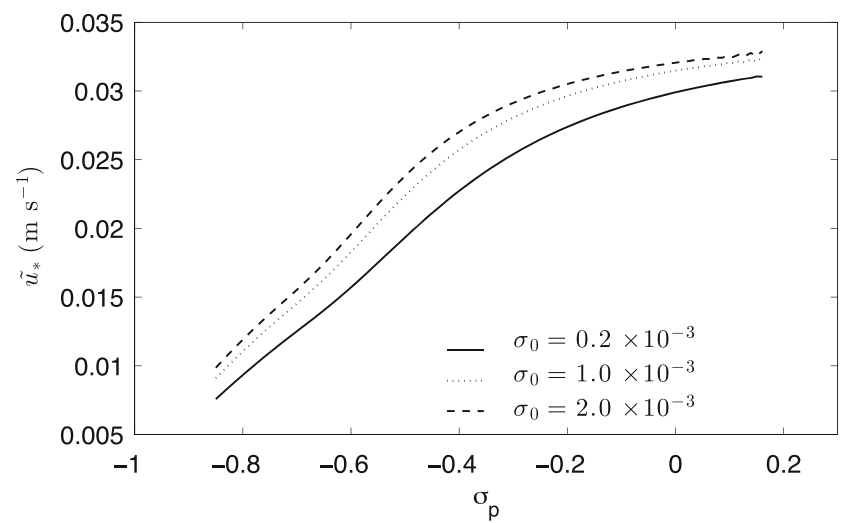

Fig. 8 The representative friction velocity $\tilde{u_{*}}$ computed with the model for $n=2$ and $r_{a}=0.01$ for different values of the dimensionless roughness length $\sigma_{0}$ 


\section{Discussion}

\subsection{Interpretation of $\sigma_{p}$}

The physical meaning of $\sigma_{p}$ is linked to the degree of stratification in the water column. This can be understood as follows. Note that a decrease of $\sigma_{p}$ in the model implies a smaller thickness of the lower layer and a smaller value of the maximum value of the eddy viscosity, $A_{I}$ (see Figs. 1 and 2). This means that the length scale of turbulent eddies generated by bottom friction decreases with decreasing $\sigma_{p}$. As this is what typically happens if stratification increases, a relationship was sought between $\sigma_{p}$ and a measurable parameter that quantifies stratification, viz. the estuarine bulk Richardson number (Dyer 1997)

$R_{i}=g \frac{\Delta \rho H}{\rho_{0} U_{m}^{2}}$.

In this expression, $\Delta \rho$ is the residual density difference between bottom and surface, $\rho_{0}$ the reference density and $U_{m}$ is the depth averaged tidal current amplitude. Thus, for different field sites values of $R_{i}$ and $\sigma_{p}$ were determined from the observations. Results reported by Bowden and Sharaf El Din (1966) for the Mersey Estuary, Jay and Musiak (1996) for the Columbia River Estuary, Geyer et al. (2000) for the Hudson River Estuary, Li and Zhong (2009) for the Chesapeake Bay and Basdurak et al. (2013) for the channel of James River Estuary, were used. Values of $R_{i}$ were obtained from measured tidal current speed and bottom-to-top density differences (see Appendix B for the data). Values of $\sigma_{p}$ were taken such that at each site the eddy viscosity profile in Eq. 7 mimicked the tidally mean eddy viscosity profile, as was reconstructed from observed shear stresses and velocity shear, or calculated from the numerical model. The results are shown in Fig. 9. Indeed, it reveals a relationship between $\sigma_{p}$ and $R_{i}$, viz. $\sigma_{p}=$ $\left[\exp \left(a R_{i}{ }^{b}\right)\right]^{-1}-1$ with $a=0.78, b=0.36$ and with a goodness of fit coefficient $\left(r^{2}\right)$ of 0.86 .

Further important insight into the meaning of parameter $\sigma_{p}$ is obtained as follows. By application of a Taylor expansion, the modelled eddy viscosity near the bottom reads

$\left.A_{v}\right|_{\sigma=-1+\tilde{\sigma}}=\left.A_{v}\right|_{\sigma=-1}+\left.\frac{\tilde{\sigma}}{h} \frac{\partial A_{v}}{\partial \sigma}\right|_{\sigma=-1}+\ldots=\tilde{\sigma} \tilde{u_{*}} \kappa\left(1+\sigma_{p}\right)+\ldots$,

in which $\tilde{\sigma}=(h+z) / D$ is a small relative height above bottom. This means that the flow close to the bottom is logarithmic with a "modified" von Karman's constant $\kappa\left(1+\sigma_{p}\right)$. Based on Fig. 9, it follows that $\sigma_{p}$ decreases with increasing stratification. This finding is consistent with that found by Wang (2002), in which the modified von Karman's constant reads $\kappa\left(1+A R_{f}\right)^{-1}$. Here, $A$ is an empirical constant that does not depend on $R_{f}$, the latter being the flux Richardson number, which is given by Mellor and Yamada (1974) as a function of the so-called gradient Richardson number $R_{g}$ as

$R_{f}=0.725\left[R_{g}+0.186-\left(R_{g}^{2}-0.316 R_{g}+0.0346\right)^{1 / 2}\right]$.

In the present study, it was assumed that $R_{i} \simeq R_{g}$, following Dyer (1997). Equating the two expressions for the modified von Karman constant yields a relation between $\sigma_{p}$ and $R_{f}$, viz.

$\sigma_{p}=\left(1+A R_{f}\right)^{-1}-1$.

Constant $A$ was subsequently calculated by application of a least square fit computed via Eqs. 15 and 16, with $R_{i}$ from the corresponding field data. The computed $A=6.7$ is close to values reported in earlier studies (Anwar 1983; Wang 2002).

\subsection{Interpretation of $r_{a}$}

The behaviour of eddy viscosity is determined by sources of turbulent mixing. For bottom-generated turbulence in an unstratified water column, the turbulent velocity scale is the friction velocity. As was argued by Stacey et al. (1999), in shallow estuaries, the turbulent velocity decreases linearly towards the surface, as in the absence of a wind stress there is no stress at the latter location. Assuming the length scale of the eddies to be the distance above the bottom, the parabolic eddy viscosity profile is found, which is used in many studies (Burchard and Hetland 2010; Zitman and Schuttelaars 2012). However, there might be additional

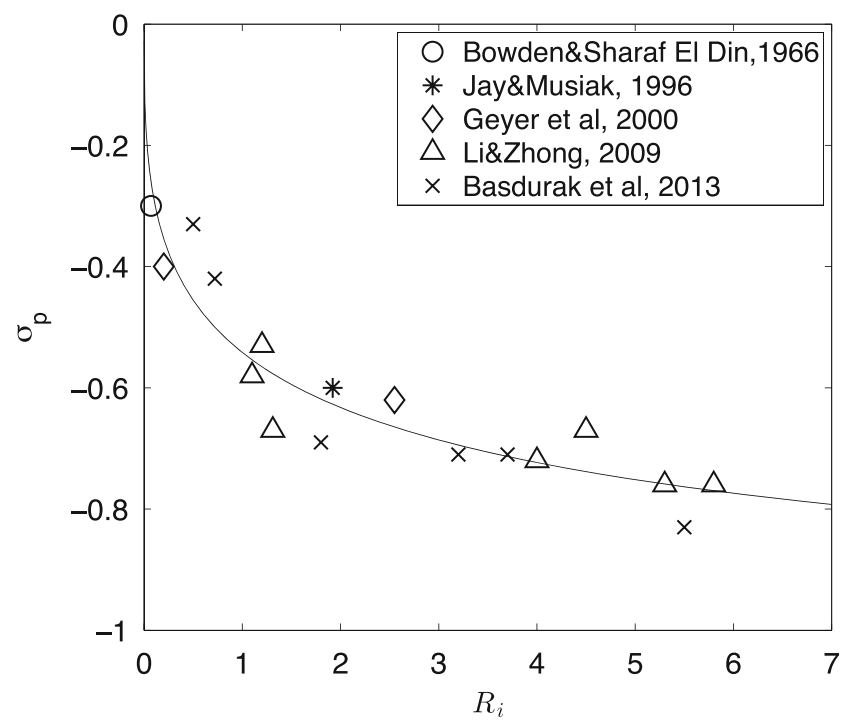

Fig. 9 Relationship between bulk Richardson number $R_{i}$ and $\sigma_{p}$ as traced from field studies and outcome of numerical models. The black line is the fit $\sigma_{p}=\left[\exp \left(-0.78 R_{i}^{0.36}\right)\right]^{-1}-1$ 
sources of turbulent mixing at the water surface, viz. breaking waves (whitecapping), wind stress, etc. To account for these sources, the eddy viscosity profile is modified such that $A_{v}(\sigma=0) \neq 0$. Thus, parameter $r_{a}$, defined as the ratio of the eddy viscosity at the surface and the maximum eddy viscosity in the water column, measures the relative importance of surface mixing.

\subsection{Physical conditions resulting in surface jumps and subsurface jets}

The information from the previous subsections will now be used to explain why for specific combinations of parameters $\sigma_{p}, r_{a}$ and $n$ the surface jump (SJ-I) and/or the subsurface jet (SJ-II) phenomenon occurs. The presence of SJ-I requires a subsurface extremum in the vertical shear of the tidal current amplitude. Now, consider the equation for vertical current shear, which follows from deriving Eq. 1 with regard to $\sigma$ :

$$
\frac{\partial}{\partial t} \frac{\partial u}{\partial \sigma}=\frac{1}{h^{2}}\left(\frac{\partial^{2} A_{v}}{\partial \sigma^{2}} \frac{\partial u}{\partial \sigma}+2 \frac{\partial A_{v}}{\partial \sigma} \frac{\partial^{2} u}{\partial \sigma^{2}}+A_{v} \frac{\partial^{2}}{\partial \sigma^{2}} \frac{\partial u}{\partial \sigma}\right) .
$$

If this equation is considered in the area where the current shear attains a maximum, the second term on the right-hand side is small (vanishing curvature of the current). The third term acts diffusive, therefore it reduces tidal shear. Thus, in order to have local increase of the tidal shear, it should be generated by the first term at the right-hand side. Clearly, this occurs if $A_{v, c}=\partial^{2} A_{v} / \partial \sigma^{2}$ is positive. Note that for a parabolic eddy viscosity profile, $A_{v, c}$ is negative, therefore no SJ-I occurs in this case. The same holds for the eddy viscosity profiles considered in this study if parameter $n \leq 1$. Thus, a necessary condition for the SJ-I to occur is that eddy viscosity decreases faster than linearly $(n>1)$ towards the surface. Physically, this means that for SJ-I to occur, a surface pycnocline must be present in which mixing is reduced and in which tidal shear increases. The reason why SJ-I only occurs for moderate stratification $\left(\sigma_{p} \sim-0.5-0\right)$ is that in the strongly stratified case, the maximum mixing is weak, hence $A_{v, c}$ itself is small and in Eq. 17, the first term on the right-hand side is too small to overcome the diffusive third term. Solutions of Eq. 1 for other values of $n$ support the previous analysis. Further details are shown in the Supplementary material.

The presence of a subsurface jet is related to the ratio of the thickness of the turbulent boundary layer $h_{b}$ and the water depth $h$. As was already stated in the introduction, Lamb (1932) and Prandle (1982) showed that in unstratified waters, subsurface maxima in the profile of the current amplitude of a harmonic constituent occur if $h_{b} \ll h$, where $h_{b} \sim\left(A_{v, \max } / \omega\right)^{1 / 2}$. Typically for tides, $h_{b} \sim h$ and thus the SJ-II phenomenon does not occur. However, if the water column becomes more stratified, mixing is suppressed and thus $h_{b}$ becomes smaller. This explains why the SJ-II phenomenon in the present model occurs for small values of $\left(1+\sigma_{p}\right)$. The value of $r_{a}$ does not control the occurrence of SJ-II, as long as it is within the imposed range $0 \leq r_{a} \leq 1$. This is because for strong stratification the maximum mixing $A_{v, \max }$ is small, hence also surface mixing will be small. Furthermore, note that the presence of SJ-II is also independent of the value of $n$; the physical control parameter is $h_{b} / h$, which in this model is controlled by $\sigma_{p}$ (stratification) and the magnitude of the pressure gradient force (which affects friction velocity $\tilde{u}_{*}$ ).

\subsection{Comparison of modelled and observed vertical structures of tidal current amplitudes}

So far, model results have been shown for fixed values of parameters, like depth and pressure gradient force (see Table 1). As is shown in Fig. 5, regimes were identified in the $\sigma_{p}-r_{a}$ parameter space for which the model simulates the SJ-I and/or SJ-II phenomenon. An important question to address is whether the model is also able to mimic the SJ phenomena for parameter values that are representative for the sites where these phenomena were actually observed.

First, the case of Liverpool Bay was investigated, where the observed tidal current profile shows an SJ-I phenomenon (Heaps and Jones 1981). The depth $h=44 \mathrm{~m}$ was obtained from their paper. Time series of observed salinity data were obtained from Simpson et al. (2002), whose field site LB2 is close to that of Heaps and Jones (1981). Thus, the tidally mean bulk Richardson number as defined in Eq. 13 was estimated by assuming that stratification was similar at the two locations. Here, $\Delta \rho=\beta \Delta S$, where $\Delta S$ is the tidally mean top to bottom salinity difference and $\beta$ being the saline contraction coefficient $\sim 0.78 \mathrm{~kg} \mathrm{~m}^{-3} \mathrm{psu}^{-1}$. For these parameter values, the regions in the $\sigma_{p}-r_{a}$ parameter space where the SJ-I/II phenomena occur are similar as those computed by the model with the default parameter setting (Fig. 5b). The value of $\sigma_{p}$ that corresponds to $R_{i}$ was obtained from Fig. 9. The result is $\sigma_{p}=-0.21$, which falls in the regime where SJ-I is found (see Fig. 5). The pressure gradient was prescribed such that the depth averaged eastdirected tidal current amplitude was similar to that observed by Heaps and Jones (1981). The surface turbulent parameter $r_{a}$ was calculated by application of a least square fit between the observed and the modelled velocity in the upper water column. With $r_{a}=0.01$, the model captures the SJ-I phenomenon (see Fig. 10a) shown by Heaps and Jones (1981). Note that $r_{a}$ may vary due to time variations in wind stress and whitecapping. The results of Fig. 5 indicate that if $n=2$ and $r_{a}>0.4$ (surface mixing that is larger than approximately $40 \%$ of the maximum mixing induced by tides) or $n \leq 1$, then the subsurface jet will vanish. The model result 
Fig. 10 Vertical profile of the tidal current amplitude.

Observed values are represented by stars $*$ and model results are represented by black lines. a The comparison between the model profile and that reconstructed from field data by Heaps and Jones (1981) at a site in Liverpool Bay. b As (a), but for at location close to station CS3 in the Yangtze Estuary (Jiang et al. 2013)
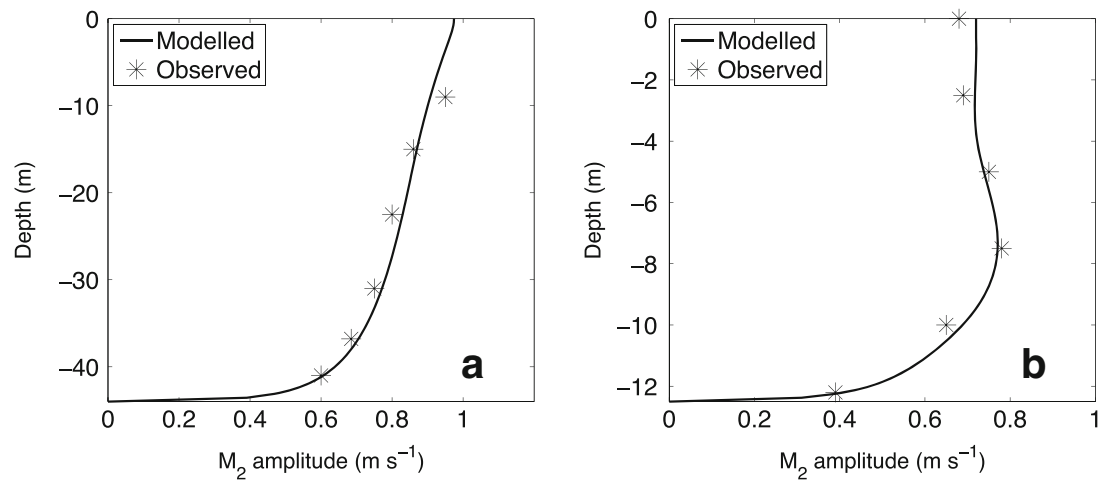

suggests that in this specific case, $r_{a}=0.01$, so surface mixing is weak. This is consistent with the weak wind of $2.5 \mathrm{~m} \mathrm{~s}^{-1}$ (weatherspark.com) during the 12-h data taken in April 8 to 9, 1977 (Wolf 1980). Average wind conditions at this site are a factor 3 larger, thus resulting in larger $r_{a}$. This might explain why the SJ-I is not present in the current profile shown by Heaps and Jones (1981) for a full month of data.

Second, the case of the Yangtze Estuary was investigated, where the SJ-II phenomenon was detected by Jiang et al. (2013). The default values for mean water depth, roughness height (see Table 1) and $n=2$ were used in this case. Moreover, salinity and along-channel velocity data were obtained during the field campaign in August, 2012 at a location close to where the $\mathrm{M}_{2}$ tidal current amplitude shows a subsurface jet. A similar procedure as for the Liverpool Bay case was conducted, resulting in $\sigma_{p}=-0.78$ and $r_{a}=0.2$ for the Yangtze estuary. Figure 10b shows that the model is able to capture the observed profile of the tidal current amplitude. The subsurface maximum is also found for the tidal current amplitude during neap tide in the dry season at the same location. It implies that this is a persistent phenomenon in the Yangtze estuary. As the data were obtained in the estuarine turbidity maximum region, sediment-induced stratification is important in causing the decrease of the bottom boundary layer height (Song and Wang 2013).

\subsection{Effect of earth rotation on tidal current profiles}

The earth rotation causes veering of tidal current with depth. To account for this, an extension of the model to two horizontal directions was made, following (Bowden et al. 1959; Prandle 1982; Soulsby 1983), to study the effect of earth rotation on the results. The present work applied the derivation similar to that presented by Soulsby (1983). The complex tidal current amplitudes $\hat{U}$ and $\hat{V}$ are written as

$$
\begin{aligned}
& \hat{U}=R_{+}+R_{-} ; \\
& \hat{V}=i R_{+}-i R_{-} ;
\end{aligned}
$$

in which the anticlockwise $R_{+}$and clockwise $R_{-}$velocity vector read

$R_{ \pm}=-i \frac{g}{\omega \pm f} S_{ \pm} p_{ \pm}$.

Here, the quantities $S_{+}$and $S_{-}$represent anticlockwise and clockwise rotary components of surface gradient, respectively, and $f\left(\sim 10^{-4} \mathrm{~s}^{-1}\right)$ is the Coriolis parameter. Moreover, the complex function $p$ as introduced in Eq. 11 is also subdivided into anticlockwise $\left(p_{+}\right)$and clockwise $\left(p_{-}\right)$ components. The expressions for $p_{ \pm}$follow $p$ by replacing $\delta$ in expressions Eq. 23a, b of Appendix A by $\delta_{ \pm}$, in which $\delta_{ \pm}=\kappa \tilde{u_{*}} /[h(\omega \pm f)]$.

Soulsby (1983) showed that at the observation site of Heaps and Jones (1981) the depth mean tidal current is almost rectilinear. The surface gradient components $\left(S_{ \pm}\right)$ are therefore solved by imposing the constraint that the depth mean tidal current amplitudes are a given $U_{\text {mean }}$ and $V_{\text {mean }}=0$. The solutions become

$\hat{U}=\frac{1}{2} U_{\text {mean }}\left(\frac{p_{+}}{P_{+}}+\frac{p_{-}}{P_{-}}\right)$,

and

$\hat{V}=\frac{i}{2} U_{\text {mean }}\left(\frac{p_{+}}{P_{+}}-\frac{p_{-}}{P_{-}}\right)$.

The quantities $P_{ \pm}$are depth mean values of $p_{ \pm}$. The computed eccentricity is below $10 \%$, which is consistent with that was found in Souza (2013). It suggests that veering of the tidal current due to earth rotation is small at the site of the Heaps and Jones (1981) and that the surface jump on tidal current amplitude is still found (Fig. 11). It turns out that earth rotation slightly enhances the surface jump.

\subsection{Model limitations and potential other drivers of surface jumps and subsurface jets}

The model that is presented in this study is highly idealised. It only describes tidal flow at a specific point, so the sea surface gradient has to be imposed, rather than that it is computed by the model. Furthermore, the formulation for eddy viscosity has three independent parameters, where two 


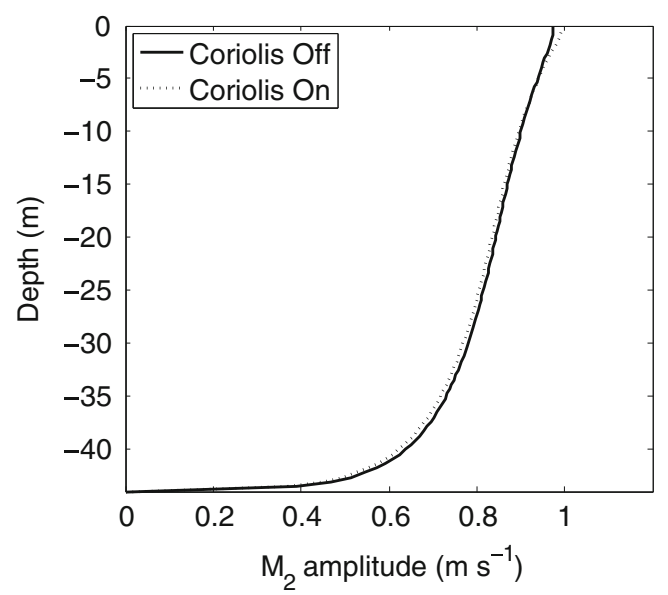

Fig. 11 Vertical profile of the $\mathrm{M}_{2}$ tidal current amplitude. Parameter values are as in Fig. 10a. Solid line and dashed line represent the result for the case without and with the Coriolis effect, respectively

of them $\left(\sigma_{p}\right.$ and $\left.r_{a}\right)$ have a clear physical meaning. Values of $n$ can only be estimated from known eddy viscosity profiles, e.g. calculated with a numerical model that employs a sophisticated closure for mixing, or reconstructed from data. Limitation of the present model is that it only allows for analytical solutions if $n=0,1$ and 2. This, however, in itself is not a serious limitation, as numerical solutions of the present model for any $n$ can be obtained by straightforward means (see Supplementary material). It has been mentioned in Section 2 that the applied linearisation approach is suitable in weakly to partially stratified water columns, where the tide is the main constituent of the water motion. In highly stratified estuaries, where residual flow is of the same order of magnitude, or even larger than tidal flow, the eddy viscosity computed by Eq. 2 is too small because the value of $\tilde{u}_{*}$ obtained by means of the imposed linearisation procedue is underestimated. Finally, it should be realised that several field studies have revealed complex vertical profiles of eddy viscosity (Bowden and Sharaf El Din 1966; Geyer et al. 2000; Basdurak et al. 2013), which can not be captured in detail by the eddy viscosity formulation that was used in this study.

It is also relevant to identify and discuss other potential drivers of surface velocity jumps and subsurface velocity jets that were not considered in this study. Before doing so, it is once more stressed (see also Section 1 that here the focus is on vertical profiles of current amplitudes of a single tidal constituent, rather than on profiles of instantaneous currents during flood and ebb, as were investigated by Jay and Musiak (1994) and Lacy et al. (2003). The crucial difference is that instantaneous currents include all tidal harmonics and consequently, a subsurface jet in an instantaneous current profile does not necessarily imply a subsurface jet in e.g. the $\mathrm{M}_{2}$ tidal current amplitude. This is apparent from
Fig. 4 of Jay and Musiak (1994), from which it can be concluded that a superposition of an $\mathrm{M}_{2}$ tidal current (showing no SJ-I or SJ-II) and a residual current that is seaward in the upper layer and landward in the bottom layer may result in a subsurface jet during flood, and in a surface jump during ebb.

A different driver of surface jumps in the current amplitude of a tidal constituent is wind. If the wind stress varies periodically in time and has a positive correlation with the direction of the tidal current induced by a specific harmonic, it will create a surface jump (SJ-I) in the current amplitude of that tidal harmonic. An area where this might occur is San Francisco Bay, where the wind has a pronounced diurnal variation and where strong diurnal tidal constituents occur (Conomos et al. 1985).

Other potential drivers of SJ-I and S-II phenomena are advection terms, which were neglected in the present study because it was assumed that the amplitude of the sea surface variations is much smaller than the depth. If advection terms are not small and the instantaneous current also contains a residual component and overtides, they affect the profile of the tidal current. The arguments below apply to the $\mathrm{M}_{2}$ tidal harmonic. As a first example, consider the advection of $\mathrm{M}_{2}$ tidal momentum by along-channel residual flow. Furthermore, assume that the tidal current amplitude decreases towards the land and that the residual flow is seaward in the upper layer and landward in the bottom layer, as is the case in many estuaries. Advection of $\mathrm{M}_{2}$ tidal momentum by this residual flow results in a reduction of the $\mathrm{M}_{2}$ current speed near the surface and an intensification of the $\mathrm{M}_{2}$ current speed near the bottom. This process thus leads to the occurrence of an SJ-II phenomenon.

As a second example, assume the advection of residual along-channel momentum by the tidal current. Consider the same conditions as in the first example, with the additional information that the residual overturning intensifies when moving into the estuary; this is typically the case at the seaward side of the salinity front. In that area, advection of residual flow by the $\mathrm{M}_{2}$ tidal current causes the $\mathrm{M}_{2}$ tidal current speed to increase in the upper layer and to decrease in the lower layer. It thus leads to an SJ-I phenomenon. Further details, as well as other examples including lateral advection of along-channel momentum, are given in the Supplementary material.

Additional potential drivers of SJ-I and SJ-II are vertical gradients of turbulent stresses that vary at the $\mathrm{M}_{2}$ tidal period and that arise from time-dependent mixing. Examples are stresses generated by the product of the $\mathrm{M}_{2}$ component of vertical eddy viscosity $A_{v}$ and a residual current shear, by the $M_{4}$ component of $A_{v}$ and $\mathrm{M}_{2}$ tidal shear, etc. In tidally dominated estuaries, which are considered in this study, these turbulent stresses are small compared to 
the turbulent stress that is retained, i.e. the one that originates from the product of the mean eddy viscosity and tidal shear. The $\mathrm{M}_{2}$ component of $A_{v}$ describes tidal asymmetry in mixing that for example results from tidal straining of the density field, by both along-channel tidal flow (Simpson et al. 1990) and lateral tidal flow (Lacy et al. 2003; Lerczak and Geyer 2004). Moreover, an $\mathrm{M}_{2}$ component in $A_{v}$ is generated by the friction velocity $u_{*}$ that results from the joint action of all tidal harmonics. The $\mathrm{M}_{4}$ component of $A_{v}$ is mainly generated by tidal variation of the friction velocity. Whether the turbulent stresses related to time-varying mixing result in SJ-I and SJ-II depends on the vertical structure of both the harmonic components of $A_{v}$ and the instantaneous current. These depend on stratification and have to be determined from the analysis of either field data or from output of numerical models.

\section{Conclusions}

The core objective of this study was to explain why at some field sites vertical profiles of observed tidal current amplitudes show either a subsurface maximum in the shear (surface jump) or a subsurface maximum in the current amplitude itself (subsurface jet). The key hypothesis was that these phenomena are related to site-specific conditions, in particular density stratification and sources of turbulence at the surface. The hypothesis was tested within the context of a new, semi-analytical model that governs the vertical distribution of tidal flow. The model contains a formulation for eddy viscosity that can mimic turbulent mixing over a wide range of stratified conditions, measured by parameter $\sigma_{p}$, which is shown to be linked to the bulk Richardson number $R_{i}$, and the amount of surface turbulence. The model results show that surface jumps occur for relatively low surface turbulence, weakly to moderately stratified conditions and if eddy viscosity in the upper layer decreases faster than linearly towards the surface (parameter $n>1$ ). In nature, this phenomenon is related to near surface mixing above a pycnocline such that tidal shear is enhanced within the pycnocline and then shear decreases toward the surface more quickly than what would otherwise follow from the law of the (surface) wall scaling. Subsurface jets occur for moderately to strongly stratified conditions. Interestingly, if $n=2$, stratification parameter $\sigma_{p}$ is between -0.5 and $-0.6\left(R_{i}\right.$ between 0.75 and 1.5$)$ and surface turbulence is weak $\left(r_{a} \leq 0.05\right)$, the model yields tidal current profiles that show both a surface jump and subsurface jet. Modelled tidal current amplitudes agree well with observations if parameter values are selected that are representative for conditions at a specific field site (depth, pressure gradient force, bulk Richardson number, bottom roughness and surface turbulence). This suggests that surface jumps and/or subsurface jets may be transient phenomena. On the other hand, field data in the North Passage of the Yangtze estuary show that subsurface jets are quite persistent.

Acknowledgments The first author is financially supported by the China Scholarship Council. This work is financed by the projects NSFC-51479074, NSFC-NWO 51061130544 (Sino-Dutch joint research). We thank two anonymous referees for constructive comments on an earlier version of the manuscript. One referee also gave useful hints with regard to the physics.

Open Access This article is distributed under the terms of the Creative Commons Attribution 4.0 International License (http:// creativecommons.org/licenses/by/4.0/), which permits unrestricted use, distribution, and reproduction in any medium, provided you give appropriate credit to the original author(s) and the source, provide a link to the Creative Commons license, and indicate if changes were made.

\section{Appendix A: The solution for $p$}

The expression for function $p$ in Eq. 11 reads as follows.

In the lower layer $\left(\sigma \in\left[-1, \sigma_{h}\right]\right)$ :

$p=1+F P_{\nu}\left(\sigma^{\prime}\right)-G Q_{\nu}\left(\sigma^{\prime}\right)$.

In the upper layer $\left(\sigma \in\left[\sigma_{h}, 0\right]\right)$ :

$p=\left(\begin{array}{ll}1+c_{1}\left[P_{v^{\prime}}\left(\sigma^{\prime \prime}\right)-\frac{P_{v^{\prime}+1}\left(\sigma_{s}{ }^{\prime}\right)}{Q_{v^{\prime}+1}\left(\sigma_{s^{\prime}}\right)} Q_{v^{\prime}}\left(\sigma^{\prime \prime}\right)\right], & n=2 \\ 1+c_{1}\left[I_{0}\left(\sigma^{\prime \prime \prime}\right)+\frac{I_{1}\left(\sigma_{s}^{\prime \prime \prime}\right)}{K_{1}\left(\sigma_{s}^{\prime \prime \prime}\right)} K_{0}\left(\sigma^{\prime \prime \prime}\right)\right], & n=1\end{array}\right)$.

Here, $P_{\nu}\left(\sigma^{\prime}\right)$ and $Q_{\nu}\left(\sigma^{\prime}\right)$ are Legendre functions of the first and second kind and $I_{n}(m)$, while $K_{n}(m)$ denote modified Bessel functions of first and second kind, respectively. Furthermore,

$$
\begin{aligned}
& F=\frac{F_{3}}{F_{1}+F_{2}}, \quad G=\frac{1+F P_{\nu}\left(\sigma_{0}^{\prime}\right)}{Q_{\nu}\left(\sigma_{0}^{\prime}\right)}, \\
& F_{1}=P_{\nu}\left(\sigma_{h}^{\prime}\right)-\frac{P_{v}\left(\sigma_{0}^{\prime}\right)}{Q_{\nu}\left(\sigma_{0}^{\prime}\right)} Q_{\nu}\left(\sigma_{h}^{\prime}\right), \\
& F_{2}=-\beta\left(\left.\frac{\partial P_{\nu}\left(\sigma^{\prime}\right)}{\partial \sigma}\right|_{\sigma_{h}}-\left.\frac{P_{\nu}\left(\sigma_{0}^{\prime}\right)}{Q_{v}\left(\sigma_{0}^{\prime}\right)} \frac{\partial Q_{\nu}\left(\sigma^{\prime}\right)}{\partial \sigma}\right|_{\sigma_{h}}\right), \\
& F_{3}=\frac{Q_{\nu}\left(\sigma_{h}^{\prime}\right)}{Q_{v}\left(\sigma_{0}^{\prime}\right)}-\left.\beta \frac{1}{Q_{v}\left(\sigma_{0}^{\prime}\right)} \frac{\partial Q_{\nu}\left(\sigma^{\prime}\right)}{\partial \sigma}\right|_{\sigma_{h}}, \\
& \beta=\beta_{1} / \beta_{2},
\end{aligned}
$$

$\beta_{1}=\left(\begin{array}{ll}P_{v^{\prime}}\left(\sigma_{h}{ }^{\prime \prime}\right)-\frac{P_{v^{\prime}+1}\left(\sigma_{s}{ }^{\prime}\right)}{Q_{v^{\prime}+1}\left(\sigma_{s}^{\prime}\right)} Q_{v^{\prime}}\left(\sigma_{h}{ }^{\prime \prime}\right), & n=2 \\ I_{0}\left(\sigma_{h}^{\prime \prime \prime}\right)+\frac{I_{1}\left(\sigma_{s}^{\prime \prime \prime}\right)}{K_{1}\left(\sigma_{s}^{\prime \prime \prime}\right)} K_{0}\left(\sigma_{h}{ }^{\prime \prime \prime}\right), & n=1\end{array}\right)$, 


$$
\begin{aligned}
& \beta_{2}=\left(\begin{array}{ll}
\left.\frac{\partial P_{v^{\prime}}\left(\sigma^{\prime}\right)}{\partial \sigma}\right|_{\sigma_{h}}-\left.\frac{P_{v^{\prime}+1}\left(\sigma_{s}{ }^{\prime}\right)}{Q_{v^{\prime}+1}\left(\sigma_{s}^{\prime}\right)} \frac{\partial Q_{v^{\prime}}\left(\sigma^{\prime}\right)}{\partial \sigma}\right|_{\sigma_{h}}, \quad n=2 \\
-\frac{2 i}{\chi_{2} \sigma_{h}^{\prime \prime \prime}}\left[I_{1}\left(\sigma_{h}^{\prime \prime \prime}\right)-\frac{I_{1}\left(\sigma_{s}^{\prime \prime \prime}\right)}{K_{1}\left(\sigma_{s}^{\prime \prime \prime}\right)} K_{1}\left(\sigma_{h}{ }^{\prime \prime \prime}\right)\right], & n=1
\end{array}\right), \\
& c_{1}=F \frac{F_{1}}{\beta_{1}}-\frac{Q_{v}\left(\sigma_{h}^{\prime}\right)}{Q_{v}\left(\sigma_{0}^{\prime}\right)} \frac{1}{\beta_{1}}, \\
& v=\frac{-\sqrt{\delta}+\sqrt{4 i+\delta}}{2 \sqrt{\delta}}, \quad v^{\prime}=\frac{-\sqrt{\chi_{1}}+\sqrt{-4 i+\chi_{1}}}{2 \sqrt{\chi_{1}}}, \\
& \delta=\kappa \tilde{u_{*}} /(\omega h), \\
& \sigma^{\prime}=\frac{2 \sigma+1-\sigma_{p}}{1+\sigma_{p}}, \quad \sigma^{\prime \prime}=\frac{i \sigma}{\sqrt{A_{S} \varrho_{1}}}, \quad \sigma^{\prime \prime \prime}=2 \sqrt{\frac{-i\left(\varrho_{2}+\sigma\right)}{\chi_{2}}}, \\
& \sigma_{h}{ }^{\prime}=\frac{2 \sigma_{h}+1-\sigma_{p}}{1+\sigma_{p}}, \quad \sigma_{h}^{\prime \prime}=\frac{i \sigma_{h}}{\sqrt{A_{S} \varrho_{1}}}, \quad \sigma_{h}{ }^{\prime \prime \prime}=2 \sqrt{\frac{-i\left(\varrho_{2}+\sigma_{h}\right)}{\chi_{2}}}, \\
& \sigma_{s}^{\prime}=\frac{1-\sigma_{p}}{1+\sigma_{p}}, \quad \sigma_{s}^{\prime \prime \prime}=2 \sqrt{\frac{-i \varrho_{2}}{\chi_{2}}}, \quad \sigma_{0}^{\prime}=\frac{2 \sigma_{0}-1-\sigma_{p}}{1+\sigma_{p}}, \\
& \chi_{1}=\delta \varrho_{1}^{-1}, \quad \varrho_{1}^{-1}=\frac{\left[\left(1+\sigma_{h}\right)\left(\sigma_{p}-\sigma_{h}\right)-A_{S}\right]}{\sigma_{h}^{2}}, \\
& \chi_{2}=\delta \varrho_{2}{ }^{-1}, \quad \varrho_{2}^{-1}=\frac{\left[\left(1+\sigma_{h}\right)\left(\sigma_{p}-\sigma_{h}\right)-A_{S}\right]}{\sigma_{h}} .
\end{aligned}
$$

If $n=0$, the expression for $p$ has the same solution structure as Eq. 22a in the lower layer but in the upper layer

$p=1+2 c_{1} \cos \left[\frac{(1+i) \sigma}{\sqrt{\chi_{3}}}\right]$ for $\sigma \in\left[\sigma_{h}, 0\right]$.

In this expression, $\sigma_{h}=\left(\sigma_{p}-1\right) / 2$. The coefficient $c_{1}=$ $\frac{\left(F P_{v}(0)-G Q_{v}(0)\right)}{2 \beta_{1}}$, in which the polynomial $F$ is a function of $F_{1}, F_{2}$ and $F_{3}$ as presented in the solutions of the case of $n=1$ and $n=2$ (see above), but with $\beta=\beta_{1} / \beta_{2}$ such that $\beta_{1}=\cos \left[\frac{(1+i)\left(\sigma_{p}-1\right)}{2 \sqrt{\chi_{3}}}\right]$ and $\beta_{2}=-\frac{(1+i)}{\sqrt{\chi_{3}}} \sin \left[\frac{(1+i)\left(\sigma_{p}-1\right)}{2 \sqrt{\chi_{3}}}\right]$, with $\chi_{3}=\delta\left(1+\sigma_{p}\right)^{2} / 2$.

In the Supplementary material, a Mathematica code is provided that allows users to calculate vertical profiles of tidal current amplitudes.

\section{Appendix B: Data used to produce Fig. 9}

Regarding the paper of Bowden and Sharaf El Din (1966), data from stations 1 to 4 were used. Because the observed sites are close to each other and results are similar, average

\begin{tabular}{|c|c|c|c|c|c|}
\hline Reference & Description & $h(\mathrm{~m})$ & $U_{m}\left(\mathrm{~m} \mathrm{~s}^{-1}\right)$ & $\Delta \rho\left(\mathrm{kg} \mathrm{m}^{-3}\right)$ & bulk $R_{i}$ \\
\hline Bowden and Sharaf El Din (1966) & & 17 & 1.38 & 0.80 & 0.07 \\
\hline Jay and Musiak (1996) & & 20 & 1.00 & 10.00 & 1.92 \\
\hline \multirow[t]{2}{*}{ Geyer et al. (2000) } & neap & 15 & 0.70 & 8.70 & 2.56 \\
\hline & spring & 15 & 1.00 & 1.50 & 0.22 \\
\hline \multirow[t]{7}{*}{ Li and Zhong (2009) } & Stat.B & 14 & 0.60 & 3.51 & 1.31 \\
\hline & Stat.A, neap & 10 & 0.30 & 5.46 & 5.83 \\
\hline & Stat.A, spring & 10 & 0.50 & 3.12 & 1.20 \\
\hline & Stat.C, neap & 20 & 0.29 & 2.34 & 5.35 \\
\hline & Stat.C, spring & 20 & 0.32 & 2.73 & 4.54 \\
\hline & Stat.D, neap & 7 & 0.28 & 4.68 & 4.01 \\
\hline & Stat.D, spring & 7 & 0.40 & 2.73 & 1.15 \\
\hline \multirow[t]{6}{*}{ Basdurak et al. (2013) } & Feb.23,04 & 15 & 1.00 & 3.50 & 0.5 \\
\hline & Sep.30,04 & 16 & 0.80 & 3.00 & 0.72 \\
\hline & Nov.04,04 & 15 & 0.50 & 6.50 & 3.75 \\
\hline & Feb.23,05 & 15 & 0.60 & 8.00 & 3.20 \\
\hline & May.18,05 & 15 & 0.50 & 9.50 & 5.47 \\
\hline & May.23,05 & 15 & 0.56 & 4.00 & 1.80 \\
\hline
\end{tabular}
values of the four stations were taken and shown. The value of parameter $\sigma_{p}=-0.3$ was estimated from their Table 4 . Regarding the paper of Jay and Musiak (1996), the value $\sigma_{p}=-0.6$ was estimated by applying their Eqs. 1 and 2.

In Geyer et al. (2000), the authors showed the eddy viscosity profiles at flood and ebb peak for both spring and neap tide. Estimates of the tidally mean eddy viscosity from

Table 2 Data, including their sources, that were used to produce Fig. 9

In the table, Stat. is Station, $h$ is depth, $U_{m}$ is depth averaged tidal amplitude, $\Delta \rho$ is tidally mean bottom-to-surface density difference and bulk $R_{i}$ is computed from Eq. 13 
these data were obtained by taking the mean values of spring and neap tide, respectively. Data and corresponding eddy viscosity values from the paper Li and Zhong (2009) were estimated from the figures by averaging over a tidal period. A similar approach was applied to obtain data from Basdurak et al. (2013). Only data from the channel was used.

Note that some of the references present top-to-bottom salinity differences. These were converted to top-to-bottom density differences by using the relation $\Delta \rho=\beta \Delta s$. The summary of all data are presented in Table 2.

\section{References}

Anwar HO (1983) Turbulence measurements in stratified and wellmixed estuarine flows. Estuar Coast Shelf Sci 17:243-260. doi:10.1016/0272-7714(83)90021-5

Basdurak NB, Valle-Levinson A, Cheng P (2013) Lateral structure of tidal asymmetry in vertical mixing and its impact on exchange flow in a coastal plain estuary. Cont Shelf Res 64:20-32. doi:10.1016/j.csr.2013.05.005

Bowden KF, Sharaf El Din SH (1966) Circulation, salinity and river discharge in the Mersey estuary. Geophys J Roy Astron Soc 10:383-399. doi:10.1111/j.1365-246X.1966.tb03066.x

Bowden KF, Fairbairn LA, Hughes P (1959) The distribution of shearing stresses in a tidal current. Geophys J Roy Astron Soc 2:288305. doi:10.1111/j.1365-246X.1959.tb05801.X

Burchard H, Hetland RD (2010) Quantifying the contributions of tidal straining and gravitational circulation to residual circulation in periodically stratified tidal estuaries. J Phys Oceanogr 40:1243-1262. doi:10.1175/2010JPO4270.1

Cheng P, de Swart HE, Valle-Levinson A (2013) Role of asymmetric tidal mixing in the subtidal dynamics of narrow estuaries. $\mathrm{J}$ Geophys Res:118. doi:10.1002/jgrc.20189

Conomos TJ, Smith RE, Gartner JW (1985) Environmental setting of San Francisco Bay. Hydrobiologia 129:1-12

Dyer KR (1997) Estuaries: a physical introduction, 2nd edn. Wiley, Chichester

Friedrichs CT, Hamrick JM (1996) Effects of channel geometry on cross sectional variations in along-channel velocity in partially stratified estuaries. In: Aubrey DG, Friedrichs CT (eds) Buoyancy effects on coastal and estuarine dynamics, vol 53. Amer. Geophys. Union, Washington, D. C., pp 283-300

Geyer WR, Trowbridge JH, Bowen M (2000) The dynamics of a partially mixed estuary. J Phys Oceanogr 30:2035-2048. doi:10.1175/1520-0485(2000)

Heaps NS, Jones JE (1981) Three-dimensional model for tides and surges with vertical eddy viscosity prescribed in two layers II. Irish Sea with bed friction layer. Geophys J Roy Astron Soc 64:303-320

Huijts KMH, Schuttelaars HM, de Swart HE, Valle-Levinson A (2006) Lateral entrapment of sediment in tidal estuaries: an idealized model study. J Geophys Res 111:C12,016. doi:10.1029/2006JC003615

Huijts KMH, Schuttelaars HM, de Swart HE, Friedrichs CT (2009) Analytical study of the transverse distribution of along-channel and transverse residual flows in tidal estuaries. Cont Shelf Res 29:89-100

Ianniello JP (1977) The distribution of shearing stresses in a tidal current. J Mar Res 35:755-786

Jay DA, Musiak JD (1994) Particle trapping in estuarine tidal flows. J Geophys Res 99:20,445-20,461. doi:10.1029/94JC00971
Jay DA, Musiak JD (1996) Internal tidal asymmetry in channel flows: origins and consequences. In: Pattiaratchi C (ed) Mixing in estuaries and coastal seas. American Geophysical Union, pp 211-249

Jiang C, de Swart HE, Li J, Liu G (2013) Mechanisms of alongchannel sediment transport in the North Passage of the Yangtze Estuary and their response to large-scale interventions. Ocean Dyn 63:283-305. doi:10.1007/s10236-013-0594-4

Johns B (1966) On the representation of the Reynolds stress in a tidal estuary. Geophys J Roy Astron Soc 12:103-110

Kajiura K (1964) On the bottom friction in an oscillatory current. Bull Earthquake Res Inst 42:147-174

Lacy JR, Stacey MT, Burau JR, Monismith SG (2003) Interaction of lateral baroclinic forcing and turbulence in an estuary. J Geophys Res 108:34-48. doi:10.1029/2002JC001392

Lamb H (1932) Hydrodynamics, 6th edn. Cambridge University Press, Cambridge

Lane A, Prandle D, Harrison AJ, Jones PD, Jarvis CJ (1997) Measuring fluxes in tidal estuaries: sensitivity to instrumentation and associated data analyses. Estuar Coast Shelf Sci 45:433-451

Lerczak JA, Geyer WR (2004) Modeling the lateral circulation in straight, stratified estuaries. J Phys Oceanogr 34:1410-71, 428. doi:10.1175/1520-0485(2004)

Li M, Zhong L (2009) Flood-ebb and spring-neap variations of mixing, stratification and circulation in Chesapeake Bay. Cont Shelf Res 29:4-14. doi:10.1016/j.csr.2007.06.012

Lorentz HA (1922) Het in rekening brengen van den weerstand bij schommelende vloeistofbewegingen. De Ingenieur 37:695-696

Mellor GL, Yamada T (1974) A hierarchy of turbulence closure models for planetary boundary layers. J Atmos Sci 31:1791-1806

Prandle D (1982) The vertical structure of tidal currents and other oscillatory flows. Cont Shelf Res 1:191-207

Ralston DK, Geyer WR, Lerczak JA (2008) Subtidal salinity and velocity in the Hudson River Estuary: observations and modeling. J Phys Oceanogr 38:753-770. doi:10.1175/2007JPO3808.1

Simpson JH, Brown J, Matthews J, Allen G (1990) Tidal straining, density currents and stirring in the control of estuarine stratification. Estuar Coast Shelf Sci 13:125-132

Simpson JH, Burchard H, Fisher NR, Rippeth TP (2002) The semi-diurnal cycle of dissipation in a ROFI: modelmeasurement comparisons. Cont Shelf Res 22:1615-1628. doi:10.1016/S0278-4343(02)00025-0

Song D, Wang XH (2013) Suspended sediment transport in the Deepwater Navigation Channel, Yangtze River Estuary, China, in the dry season 2009: 2. Numerical simulations. J Geophys Res 118:55685590. doi:10.1002/jgrc. 20411

Soulsby RL (1983) The bottom boundary layer of shelf seas. In: Johns B (ed) Physical oceanography of coastal and shelf seas, vol 35. Elsevier Science Publishers B. V., Amsterdam, pp 189-266

Souza AJ (2013) On the use of the Stokes number to explain frictional tidal dynamics and water column structure in shelf seas. Ocean Sci 9:391-398. doi:10.5194/os-9-391-2013

Stacey MT, Ralston DK (2005) The scaling and structure of the estuarine bottom boundary layer. J Phys Oceanogr 35:55-71. doi:10.1175/JPO-2672.1

Stacey MT, Monismith SG, Burau JR (1999) Measurements of Reynolds stress profiles in unstratified tidal flow. J Geophys Res 104:10,933-10,949

Stacey MT, Fram JP, Chow FK (2008) Role of tidally periodic density stratification in the creation of estuarine subtidal circulation. $\mathrm{J}$ Geophys Res 113:C08,016. doi:10.1029/2007JC004581

Wang XH (2002) Tide-induced sediment resuspension and the bottom boundary layer in an idealised estuary with a muddy bed. J Phys Oceanogr 32:3113-3131. doi:10.1175/1520-0485(2002) 
Warner JC, Geyer WR, Lerczak JA (2005) Numerical modeling of an estuary: a comprehensive skill assessment. J Geophys Res 110:C05,001. doi:10.1029/2004JC002691

Winant CD (2007) Three-dimensional tidal flow in an elongated, rotating basin. J Phys Oceanogr 37:2345-2362. doi:10.1175/ JPO3122.1

Wolf J (1980) Estimation of shearing stresses in a tidal current with application to the Irish sea. In: Nihoul JCJ (ed) Marine turbulence, proceedings of the 11th Liège international colloquium on ocean hydrodynamics. Elsevier Oceanography Series, 28, Amsterdam, pp 319-344

Zimmerman JTF (1982) On the Lorentz linearization of a quadratically damped forced oscillator. Phys Lett 89:123-124

Zitman TJ, Schuttelaars HM (2012) Importance of cross-channel bathymetry and eddy viscosity parameterization in modelling estuarine flow. Ocean Dyn 62:755-786. doi:10.1007/s10236011-0513-5 